\title{
Sea level changes and Coastal Evolution and Neotectonics: INQUA Commissions joint meeting, Taiwan, 2001
}

The Commission on Sea level Changes and Coastal Evolution of INQUA serves to facilitate and enhance the scope of collaborative research, and one of their ways of doing so is to convene a meeting of scientists in a region of key scientific importance. In October 2001, a joint meeting of this Commission with the INQUA Commission of Neotectonics was held in the tectonically active island of Taiwan. The meeting was an acknowledgement of the fact that in recent years there has been considerable research on the relationship between active tectonism, climate, surface processes and the evolution of the earth's topography. Taiwan is perhaps one of the best places on Earth to understand how active tectonism and climaticallyinduced sea level changes interact in the process of coastal evolution. The participants of the meeting together presented wide-ranging work that clearly showed the major developments in this topic area that have occurred in recent years.

This special issue of Quaternary International is a direct result of the October 2001 joint meeting in Taiwan. It contains 16 papers with a variety of subjects on coastal evolution and neotectonics. The sea level changes and coastal evolution portion is further divided into two parts: (1) coastal morphology and Quaternary tectonics, and (2) coastal environment based on paleontology. Many interesting papers are presented from studies around the world, and these are summarized in the following paragraph.

Omura et al. confirmed the MIS 5e terrace by the high-precision ${ }^{230} \mathrm{Th} /{ }^{234} \mathrm{U}$ dating in Palawan, Cebu, Bohol and Panglao islands in Philippines, and suggested that the islands have been stable since the last interglacial period. Maeda et al. described the Holocene paleoshorelines, which enables us to understand types of neotectonics in Philippines. Berdin et al. described the Holocene sea-level highstand and its implications for vertical stability of Panglao Island, southwest Bohol, Philippines. Liew et al. made an overview on the characteristics of coastal morphology of the tectonically active Taiwan island. Hsieh et al. and
Yamaguchi and Ota discussed the morphology of the high uplifting eastern coast of Taiwan. Song et al. discussed the possibility of changeable uplift rates in the eastern and northern coasts of Taiwan. Urabe et al. described the characteristics of a subsided, deformed barrier island in the central part of the Echigo Plain, which faces the Sea of Japan, central Japan based on sedimentological studies. Yabe et al. determined the timing and magnitude of paleoenvironmental changes in the Echigo Plain, Japan by examination of diatom floras in borehole cores. Hongo used pollen analyses to understand the paleoclimatic changes during a Pleistocene high sea level stand in southwest Japan. Luchi et al. present the late Quaternary ancient shorelines at Lipari by stratigraphical constraints to reconstruct geological evolution and vertical movements.

In the part of Neotectonics, a study in Eliki Fault of Greece was presented by Pavlides et al. Ota et al., as well as Chang and Yang, described the morphological characteristics of the rupture trace of the M 7.61999 Chi Chi, Taiwan Earthquake, a $80 \mathrm{~km}$ long thrust rupture, that occurred along the Chelungpu Fault of Taiwan. Chen et al. provided recurrence interval estimates for previous ChiChi-type events based on preliminary trenching of the Chelungpu Fault. One of the active fault systems in northwest part of Taiwan was also discussed in another contribution by Chen et al.

We thank all of the reviewers, Dr. Bloom, A.L., Dr. Pirazzoli, P.A., Dr. Dumas, B., Dr. Wei, K.Y., Dr. Mii, H.S., Dr. Watanabe, M., Dr. Woodroffe, C., Dr. Zong, Y.Q., Dr. Maeda, Y., Dr. Owen, L.A., Dr. Litchfield, N., Dr. Chen, Y. G., and Dr. Hsieh, M. L. of the papers that are in this volume. They made constructive comments on the science embodied in the papers, and also provided numerous helpful comments to improve papers from countries where English is not the native language.

We hope these papers will be of interest to researchers working in the fields of coastal geomorphology and 
neotectonics, and that they will stimulate further collaboration.

Ping-Mei Liew Department of Geosciences, National Taiwan University, 1, Sec. 4. Roosevelt Rd., Taipei, Taiwan, ROC
Yoko Ota

Yokohama National University, Yokohama, Japan

Mark Stirling Institute of Geological and Nuclear Sciences, P.O. Box 30-368, Lower Hutt, New Zealand 